every success but blames all problems on political meddling. Given that state intervention has produced notable successes, such as social programmes to reduce hunger, this is simplistic.

The effect is that the authors have little constructive to say about the role of politics in a world in which it inevitably mixes with markets. They fail to ask key questions. For instance, how much has public investment in transport infrastructure and agricultural research and development shaped the marketplace? And what if, rather than being ignorant of the thinking that an ever more specialized division of labour will yield ever greater health, wealth and happiness, locavores are actually challenging it?

For example, Desrochers and Shimizu celebrate the specialization in the food industry that has given us artificial sweeteners to fight type 2 diabetes. But that specialization has also given us abundant empty calories and poverty-wage work, which contribute to the incidence of diet-related diseases. Local food won't solve public-health problems, true, but the authors' critique leaves us no wiser or fitter. If, as they say, "the essence of progress is to create less significant problems than those that existed before", should we just be thankful that we're fat rather than hungry?

The authors' confidence that the system works sits oddly against evidence that above a certain point, growth in gross domestic product is not correlated with improved well-being. At the core of progressive locavore thinking are efforts to address this by questioning the association between material consumption and prosperity, pushing use of renewable resources and reducing economic inequalities.

By hanging their argument on the advantages that we enjoy over our ancestors, Desrochers and Shimizu give us little more than an entertaining defence of business as usual. The UK government's unlocavorish Foresight unit, which advises on how to future-proof policy decisions, found last year that "nothing less is required than a redesign of the whole food system to bring sustainability to the fore". Desrochers and Shimizu's prescription not to mess with the market seems a missed opportunity to say something altogether more imaginative and more useful. Locavores don't have a blueprint, but we should welcome the ingenuity and challenge that they bring to this urgent redesign..

Tom MacMillan is director of innovation at the Soil Association in Bristol, a UK charity that campaigns for planet-friendly food and farming. e-mail:tmacmillan@soilassociation.org

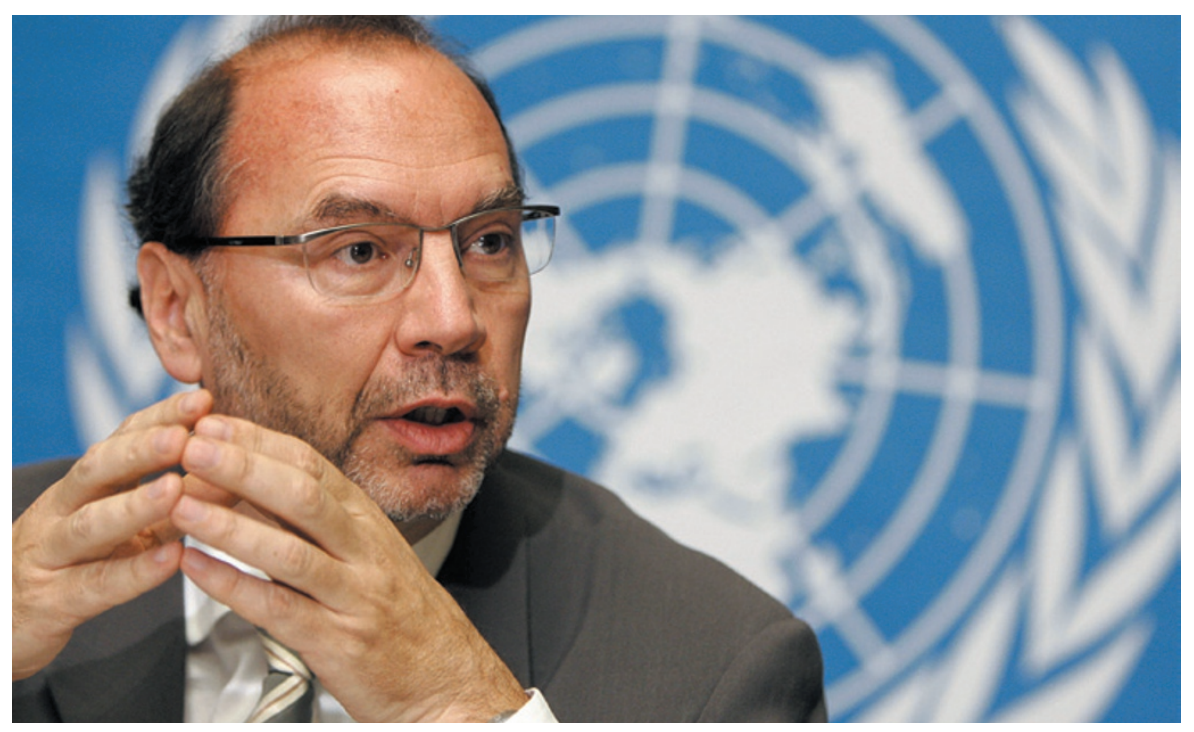

Peter Piot co-discovered the Ebola virus and helped to coordinate the global response to HIV and AIDS.

\title{
VIROLOGY
}

\section{The battle inside}

\section{José Esparza enjoys the memoir of a long-term veteran of the virus wars.}

$\mathrm{I}$ 1933, Nobel-prizewinning physician Charles Nicolle said that infectious diseases "carry the traits of life that seeks to perpetuate itself, evolving and trying to achieve equilibrium". But this evolution has a high price for humans. The war between human and microbe is epic and ongoing.

In No Time to Lose, Peter Piot, director of the London School of Hygiene and Tropical Medicine, offers chronicles of two battles from that war: his front-line fights against the Ebola virus, which can trigger a highly lethal haemorrhagic fever, and HIV. The book does not pretend to be a history of those viruses, or a technical manual on infectious diseases generally. It is a memoir - although intertwined with epidemiology, science and politics - and, as such, it is Piot's prerogative to remember and to recognize what he chooses.

We witness Piot's evolution over 35 years, from idealistic young medical scientist in Belgium to skilful United Nations politician and diplomat in Geneva, Switzerland, as director of the Joint United Nations Programme on HIV/AIDS (UNAIDS). Piot is not always diplomatic: he paints a wartsand-all portrait of how science is done and public health protected. And, like many good storytellers, he identifies the good guys and the villains in the threads of his narrative.

Piot's first African adventure was in Zaire, now the Democratic Republic of Congo, in 1976. He was chasing an unusual epidemic caused, he and his colleagues learned, by a

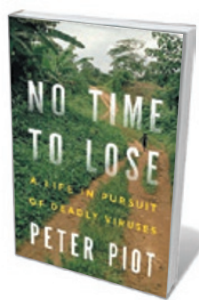

No Time to Lose: A Life in Pursuit of Deadly Viruses PETER PIOT

Norton: 2012. 304 pp. $\$ 28.95, £ 17.99$ previously undiscovered pathogen that came to be known as the Ebola virus. As Piot works towards an understanding of Ebola haemorrhagic fever, the story becomes the stuff of high drama: the writing is so vivid that I felt as if I were beside Piot in the Congolese jungle.

The epidemic Piot witnessed was fast and furious, killing 431 people in Zaire and Sudan in the last four months of 1976. As it raged, Piot began to absorb the realities of research: the tensions between competition and collaboration and the need for priority recognition of scientific discoveries. He also started to learn how to communicate with affected populations, including Belgian nuns in the small village of Yambuku, Zaire, four of whom succumbed to Ebola. Rather than just studying it as a pathological phenomenon, Piot probed the epidemic's human dimension - an essential component of modern epidemiology.

During the epidemic, Piot collaborated and competed with several US scientists. These encounters led him to study sexually transmitted infections with epidemiologist King Holmes in Seattle, Washington. 
- He was at the University of Washington for a little more than a year, but this period was a turning point for Piot, preparing him for his next challenge: the emerging AIDS epidemic. It was to absorb the next 30 years of his life.

Now pursuing HIV, Piot returned to Kinshasa. In 1984, he and his collaborators established Project SIDA, which produced most of the early information on AIDS in Africa. The project was led at first by the epidemiologist Jonathan Mann; in 1986, Mann became the first director of the Global Programme on AIDS of the World Health Organization (WHO).

Piot details the personal differences and changing focus that led to the dissolution of the Global Programme and the launch of UNAIDS. Piot served as its first director from 1996 until 2008 - a period that makes up the bulk of the book. A more definitive overview of these years appears in AIDS at 30 (Potomac, 2012) by Victoria Harden, a historian at the US National Institutes of Health.

Piot resolved that on the research front, UNAIDS would focus on epidemiology. But it also ran many other activities, particularly coordination of the country-level response to AIDS.

Piot's main focus was advocacy, community mobilization, political sensitization and fund-raising, and he found success. I am disappointed, however, that as a medical scientist, he does not

"Despite the efforts of virus hunters, neither Ebolanor HIV is under control." use his book to discuss the enormous research effort behind the antiretroviral drugs that significantly improved the prognosis of people living with HIV. Nor does he discuss the other biomedical efforts, including vaccines, which I believe will have a key role in stopping the epidemic.

Despite the efforts of virus hunters, neither Ebola nor HIV is under control. These viruses continue to strive for the equilibrium suggested by Nicolle. By May 2011, 28 outbreaks of viruses in the Ebola family had occurred in 11 countries, with a total of 2,288 human cases. And by the end of 2010, an estimated 34 million people worldwide were living with HIV.

This book is not the story of two diseases. Rather, it is a fascinating account of the complex behavioural responses that epidemics trigger among their human hosts. -

José Esparza is senior adviser on vaccines for the Bill \& Melinda Gates Foundation in Seattle, Washington.

e-mail: jose.esparza@gatesfoundation.org

PSYCHOLOGY

\section{Markets in mind}

\section{Investment bankers are addicts on a steroid roller coaster, finds Richard Lea.}

$\mathrm{R}$ ené Descartes may have sparked the Enlightenment when he proposed that thought is the basis for existence, but Cartesian mind-body dualism has fallen out of favour in philosophy. According to neuroscientist John Coates, however, there is one domain in which the idea of a mind driven by pure rationality persists: economics.

In The Hour Between Dog and Wolf, Coates tests this to breaking point, with an area of economics where rationality does not rule. Using physiology and neuroscience, and grounded by 12 years working in New York's financial district, Coates paints a vivid picture of stockbrokers as thrill junkies, surfing waves of boom and bust on steroid hormones.

Coates suggests ways to calm those waves, but his prescription doesn't go far enough. $\mathrm{He}$ focuses on strategies for controlling the testosterone highs of the "Masters of the Universe" — as Tom Wolfe styled them in The Bonfire of the Vanities (Farrar, Straus and Giroux, 1987) — instead of restructuring a financial system that currently "balances precariously on the mental health of these risk takers".

Coates begins with a vibrant portrait of a Wall Street investment bank as the markets prepare for an interest-rate announcement. He conjures up the excitement of the trading floor, a "parabolic reflector" gathering information and registering early signals. Traders pick up on this information through a hunch or gut feeling, and act on it fast.

Alongside some novelistic vignettes - the head of department surveying the floor like a hound on the scent - Coates describes the neurological and physiological changes that bankers experience. For example, when stockbrokers hear a rumour that interest rates will rise, their brains put them into high alert: they "hear the faintest sound, notice the slightest movement". Their metabolisms accelerate, breathing quickens and blood shunts to major muscle groups. Their bodies are flooded with adrenaline and testosterone.

Turning to the dialogue between brain and body, Coates says that physiology is key in decision-making. Decisions imply action, so "our thoughts come freighted with physical implications". Traders, like soldiers, make snap decisions with much at stake, so they must listen to the signals from their bodies.

Coates presents his own research from a London firm. He found a link between traders' morning levels of testosterone and afternoon profits, as well as a substantial increase
The Hour Between Dog and Wolf: Risk-taking, Gut Feelings and the Biology of Boom and Bust JOHN COATES

Fourth Estate/Penguin: 2012. 288/352 pp. $£ 20 / \$ 27.95$

When testosterone levels rise during a bull market, with successes following each other so rapidly that there is no time for hormone levels to return to normal, stockbrokers can fall prey to the "irrational exuberance" that powers a bubble. During a declining 'bear' market, sustained levels of cortisol can fuel the panic before a crash and even, Coates suggests, contribute to hypertension and type 2 diabetes in individuals. A system that evolved to respond to physical threats over seconds or hours - the leopard in the forest, the rival in the group - is unable to cope with threats that evolve over weeks or months.

The drawbacks of Coates's familiarity with the trading floor become plain when he proposes fixes. Perhaps traders will be less stressed if they practise yoga or take up a wind instrument as he suggests, but his broader solutions - such as restraint from middle management, increased gender equality and the sinister idea of sending traders home on the results of a morning blood test - seem inadequate as counters to the powerful physiological influences on decision-making.

Coates's other solutions need some rethinking too. His idea of offering traders rewards on the basis of long-term results should be extended to managers and companies. Instead of adding "audio price feeds" to the trading floor to decrease traders' reaction times, a financial-transaction tax should be introduced to reduce market volatility.

If market swings are as driven by hormones as Coates suggests, it is not enough for politicians to step in when stress in the financial world has become pathological. They must decouple irrational exuberance on Wall Street from misery on the high street. Readers reeling from the effects of the most recent financial Armageddon may feel that the Universe needs some new masters.

Richard Lea is a journalist on the books desk at The Guardian in London. e-mail: richard.lea@guardian.co.uk 